\title{
Molecular Characterization of Staphylococcus Haemolyticus Isolated from Vaginitis and Some of Their Virulence Factors
}

\author{
Enas R. Alwaily ${ }^{1}$, Ruaa M. Khazaal ${ }^{2}$, Mohammed H. Flaih ${ }^{3 *}$ and Khwam R. Hussein ${ }^{4}$ \\ \{Enas.Kazem@alayen.edu.iq ${ }^{1}$, Ruaa.m1982@stu.edu.iq ${ }^{2}$, moh.alqurayshi@stu.edu.iq ${ }^{2 *}$, \\ krhussein@stu.edu.iq ${ }^{3}$ \} \\ College of Pharmacy, Al-Ayen University, Al-Nasiriyah, 64001, Iraq ${ }^{1}$ \\ Department of Medical Laboratory Techniques, Al-Nasiryah Technical Institute, Southern Technical \\ University, Al-Nasiriyah, 64001, Iraq ${ }^{2,3}$ \\ Department of Nursing, Al-Nasiryah Technical Institute, Southern Technical University, Nasiriyah, \\ 64001, Iraq $^{4}$
}

\begin{abstract}
Vaginitis is still considered to be a global health problem for females. It is mainly occurred by bacterial vaginosis, trichomonal, candidal, and gonococcal vaginal infections. This study is aimed identify Staphylococcus haemolyticus in females infected with vaginitis and determine some of their virulence genes. A total of 250 vaginal swabs were collected from females with vaginitis. Of the 250 vaginal swabs, 40 isolates were showed bacterial growth of S. haemolyticus. In susceptibility testing, S. haemolyticus isolates were sensitive to some antibiotics, whereas other isolates were resistant. The amplified 16S rRNA gene was in all isolates, using conventional PCR, icaA, blaz, mecA, and SodA genes were detected in 30, 23, 32, and 24 samples, respectively. The sequencing analysis of all local isolates appeared slight mismatching in their sequencing. The PCR products of virulence factors of S. haemolyticus showed slight variations. This may explain different clinical manifestations and the infection severity.
\end{abstract}

Keywords: 16S rRNA, S. haemolyticus, antimicrobial susceptibility, resistance genes, virulence genes.

\section{Introduction}

Vaginal infections (vaginitis) are mainly included bacterial vaginosis, trichomonal, candidal, and gonococcal vaginal infection which are a global problem for females [1]. This infection is characterized by symptoms such as vulvovaginal pain, itching, and burning. The diagnosis of the disease depends on the presence of yellow purulent WBCs (10 cells per field), and the existence of endocervical bleeding resulting from ersioned tissue [2]. The molecular diagnosis of vaginitis causative agents has proven that practical and can increase the accuracy more than cultures, also for detecting low levels of fungi [3], [4]. The molecular diagnosis approaches of the three major common causes of vaginitis are now available, depending on the collection of 1-2 vaginal swabs [4]. Staphylococci consider as bacterial normal flora that colonizes the human skin and mucosal membranes and cause opportunistic infection. However, S. haemolyticus returns to the Staphylococcus epidermidis group [coagulase-negative Staphylococci] that is mostly isolated from the axillae, perineum, also from human inguinal areas [5]. It can cause a local or systemic infection. Since its high antibiotic-resistant phenotype and the ability to the formation of biofilms make S. haemolyticus more resistant to the drug [6], [7]. However, S. haemolyticus biofilms are polysaccharide intercellular adhesin [1] that may be used for determining S. haemolyticus isolates from biofilm structure [8], [9]. 
S. haemolyticus genome contains a chromosome and three plasmids. The size chromosome is near form $\mathrm{S}$. aureus and $\mathrm{S}$. epidermidis and has a $\mathrm{G}+\mathrm{C}$ similar content [5]. S. haemolyticus genome also contains many insertion sequences [ISs], those elements may promote frequent genomic rearrangements which accelerate the diversification of the species. Theoretically, these adaptations might help S. haemolyticus overcome the adverse effects of chemical exposure [10]. In molecular diagnosis, the $16 \mathrm{~S}$ rRNA gene is mostly used to the identity of bacteria spp. for many reasons, [i] nearly, it is found in all bacteria [ii] the function of the 16S rRNA gene does not change with overtime, this meaning random sequence changes are a more accurate measure of evolution and [iii] the $16 \mathrm{~S}$ rRNA gene $(1,500 \mathrm{bp})$ is a large fragment enough for informatics purposes [11]. Generally, there is little information about a molecular aspect of vaginitis causative agents, so the current study is aimed to identify and to characterize S. haemolyticus isolated from females, as the main causative of vaginitis and define some of the genetic determinants of virulence factors of these isolates.

\section{Materials and methods}

\subsection{Samples Collection}

Vaginal swabs were collected from 250 female patients who attended the consulting clinic at Bint Al-Huda Hospital of the Maternity and Children in Al-Nasiriyah city at Thi-Qar province southern Iraq, from the beginning of February to the end of December 2020. The age of the patients is ranged between 17-50 years. However, two vaginal swabs were taken from each patient, then transported to the laboratory after inoculating these swabs into sterile tubes containing a transport medium, one of the swabs was directly exanimated via staining with Gram stain and wet mounted film, and another swab was used for inoculation onto the SDA medium, CHROM agar for Candida, CHROM agar orientation CHROM agar for Staphylococci, Eosin methylene blue agar, MacConkey's agar, for microbiological investigation and phenotypic diagnosis. The biochemical tests were accomplished by Vitek 2 system. The susceptibility test was carried out using the disk diffusion method according to CLSI [12].

\subsection{Ethical Agreement}

It was obtained from University Committee (Al-Ayen University). Participants in the study were volunteers. The written consent was taken from all patients who were free to withdraw at any time.

\subsection{Genomic Extraction}

All of S. haemolyticus isolates were subculture in BHI broth $(10 \mathrm{~mL})$ and incubated at $37^{\mathrm{C}} \mathrm{C}$ overnight, then centrifuged $(8000 \mathrm{xg})$. The sediment was collected to extract the genomic DNA according to kit user manual guidelines (Geneaid, Taiwan). Using a Nanodrop spectrophotometer, DNA concentration and purity were checked. The extracted DNA was preserved by freezing at $-20^{\circ} \mathrm{C}$ until used in PCR amplification.

\subsection{Molecular Diagnosis and DNA Sequencing}

Using NCBI-Gene Bank database and Primer 3 design online, all PCR primers of blaz, icaD, mecA, and SodA genes were designed and supplied by Macrogen Company, Korea. The 16S rRNA gene forward primer: CGTGGAGGGTCATTTGGGAA, and reverse primer: GTTTGTCACCGGCAGTCAAC (559bp), SodA gene F: TCTGCAGTTGAGGGAACAGA, R:AACCTGAACCGAAACGAGCT (262bp), icaA gene F: ATGGTCAAGCCCAGACA GAG, R: ACAAACAAACTCATCCATCCGA (236bp), blaz gene F: TGCTTCGACTTCA AAAGCGA, R:GGTTCAGATTGGCCCTTAGGA (564bp), and mecA gene F: TGGCCAA TACAGGAACAGCA, R: CGTCAACGAT TGTGACACGA (426bp). The PCR master mix was provided by AccuPower®PCR PreMix kit (Bioneer, Korea). The PCR master mix 
components included $5 \mu$ of DNA template, $1.5 \mu \mathrm{l}$ of each F and R primers, and $12 \mu \mathrm{l}$ of nuclease-free water that was placed in a standard PCR tube. The PCR thermocycler conditions were an initial denaturation set at $95^{\circ} \mathrm{C}$ for five min, then 30 cycles as followed denaturation set at $95^{\circ} \mathrm{C}$ for $20 \mathrm{~s}$., annealing was $60^{\circ} \mathrm{C}$ for $20 \mathrm{~s}$. of $16 \mathrm{Sr}$ RNA, fnbA, icaD genes, $58^{\circ} \mathrm{C}$ for $20 \mathrm{~s}$. of Sod A, MecA genes and $61^{\circ} \mathrm{C}$ for $20 \mathrm{~s}$ of blaz gene and extension set at $72^{\circ} \mathrm{C}$ for one min. The final extension was at $72^{\circ} \mathrm{C}$ for five min. PCR products were electrophoresed with Agarose gel $(1 \%)$ and bromide ethidium $(0.25 \mu \mathrm{g} / \mathrm{ml})$. DNA ladder $(100 \mathrm{bp})$ (Bioneer) was used as a molecular marker for each gel. The gel was photographed at a UV Transilluminator [13].

The DNA sequencing was applied as a confirmative identification for PCR positive samples and to analyse the phylogenetic relationships. The visualized gene isolates were purified using a gel purification kit and then sent to Macrogen Company in Korea to perform the sequencing of DNA. The phylogenetic tree analysis was performed using the Maximum Likelihood Process and Molecular Evolutionary Genetics Analysis using MEGA V. 6 software.

\subsection{Statistical Analysis}

The study data were analysed with SPSS version 23 [the chi-square test]. A statistical significance was accepted if $\mathrm{p} \leq 0.05$.

\section{Results and discussion}

Of the 250 vaginal swabs, 130 isolates were showed bacterial growth and 100 isolates were showed fungal growth, whereas 20 isolates did not appear any growth. A total of 40 out of 250 cultured vaginal swabs were classified as S. haemolyticus isolates. A high number of the isolates were observed as sensitive for meropenem, imipenem, ciprofloxacin, cefotaxime, cefixime. Additionally, another number of antibiotic-resistant isolates is showed in Table (1). Most of the $\mathrm{S}$. haemolyticus isolates were sensitive to fluoroquinolones, carbapenems, quinolones. The statistical analysis data showed insignificant differences $(\mathrm{P}=0.00)$. However, high multidrug resistance may return to difficulty in biofilm penetration (protective nature of biofilm) by antibiotics, the slow growth rate of the bacteria, and the presence of antibiotic degradation mechanisms [15]. These findings are like the study of Goldenberg et al. [14], also agree with the results of Guta [16] but vary on other S. haemolyticus strains that were isolated from nonvaginal environments [17]. The high antibiotic resistance may return to the random and excessive use of antibiotics that leads to creating the resistant strains, these results are very important when the physician begins prescribing the correct antibiotic for treatment. The antibiotic resistance is occurred by increased Biofilm formation that mostly leads to persistent infections [18], [19].

\subsection{Molecular Identification and Sequencing of 16S rRNA Gene}

The amplification of $16 \mathrm{~S}$ rRNA products appeared in all 40 bacterial isolates of S. haemolyticus at $559 \mathrm{bp}$ as shown in Fig 1 . The $16 \mathrm{~S}$ rRNA gene contains the $30 \mathrm{~S}$ subunit region of the ribosome of prokaryotic and is a universal gene where find in all bacteria spp. It is very useful for the reconstruction of phylogenies because of the evolutionary slow rate of this gene. 16S rRNA is used for conferring the relatedness of diverse bacteria and for the determination of the species. The similarity percentage of $16 \mathrm{~S}$ rRNA among species (to define them as identical species) is 98.7\%. In Staphylococci, the 16S rRNA gene is very similar across species, as a result, two different species can have identical 16S rRNA sequences [20],[21]. The guidelines of bacterial classification proposed the strains that have lower than $97 \%$ 16S rRNA sequence identity be considered as different bacterial species [22]. The sequencing analysis of local isolate [MW485615] revealed that there were differed in only two nucleotides in their linear sequenced DNA, and the 16S rRNA sequence showed a very high similarity (99\%) between these two local isolates and NCBI-BLAST S. haemolyticus SH1 strain [MK886483.1], this result is agreed with the study of Ghebremedhin et al. [23]. Both local isolates were recorded in NCBI BLAST GenBank as a global scientific website with accession numbers MW485614 and MW485615 
respectively. The phylogenetic tree as represented in Fig 2 revealed high bootstrap values of 99\% with MK886483.1 isolate.

Table 1. Antimicrobial resistance to $S$. haemolyticus isolated from vaginitis.

\begin{tabular}{|c|c|c|}
\hline Antimicrobial & ${ }^{*} \mathrm{~S}(\%)$ & $\mathrm{R}(\%)$ \\
\hline \multicolumn{3}{|l|}{ Penicillin group: } \\
\hline Amoxicillin, clavulanicacid,AMC & $15(37.5)$ & $25(62.5)$ \\
\hline Methicillin & $6(15)$ & $34(85)$ \\
\hline \multicolumn{3}{|l|}{ Cephalosporins: } \\
\hline cephalothin, KF & $10(25)$ & $30(75)$ \\
\hline cefixime, CFM & $31(77.5)$ & $9(22.5)$ \\
\hline Cefotaxime, CTX & $17(42.5)$ & $23(57.5)$ \\
\hline ceftriaxone, CRO & $26(65)$ & $14(35)$ \\
\hline \multicolumn{3}{|l|}{ Tetracycline-class : } \\
\hline doxycycline, DO & $25(62.5)$ & $15(37.5)$ \\
\hline \multicolumn{3}{|l|}{ Aminoglycoside : } \\
\hline gentamicin, $\mathrm{CN}$ & $20(50)$ & $20(50)$ \\
\hline Amikacin, AK & $19(47.5)$ & $21(52.5)$ \\
\hline Netilmicin, NET & $23(57.5)$ & $17(42.5)$ \\
\hline Nitrofurantoin, NI & $16(40)$ & $24(60)$ \\
\hline \multicolumn{3}{|l|}{ Carbapenems: } \\
\hline Imipenem, IPM & $33(82.5)$ & $7(17.5)$ \\
\hline Meropenem, MEM & $31(77.5)$ & $9(22.5)$ \\
\hline \multicolumn{3}{|l|}{ Quinolones: } \\
\hline Ciprofloxacin, CIP & $25(62.5)$ & $15(37.5)$ \\
\hline Levofloxacin, LEV & $26(65)$ & $14(35)$ \\
\hline \multicolumn{3}{|l|}{ Glycopeptide: } \\
\hline Vancomycin, V & $23(57.5)$ & $17(42.5)$ \\
\hline \multicolumn{3}{|l|}{ Sulfonamides: } \\
\hline Trimethoprim/sulfamethoxazole, TS & $21(52.5)$ & $19(47.5)$ \\
\hline \multicolumn{3}{|l|}{ Lincosamide: } \\
\hline Lincomycin, L & $25(62.5)$ & $15(37.5)$ \\
\hline
\end{tabular}

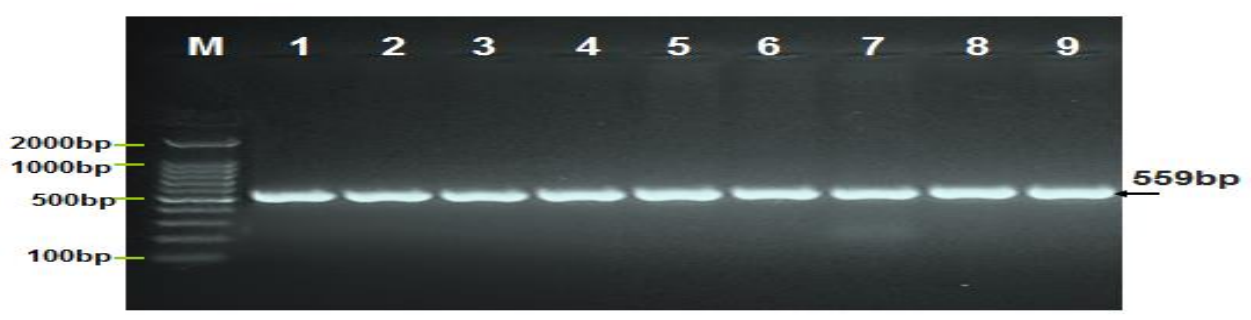

Fig. 1. Agarose gel electrophoresis of $16 \mathrm{~S}$ rRNA gene of S. haemolyticus isolates. Where Marker ladder [2000-100bp], lanes [1-9] were positive at 559bp.

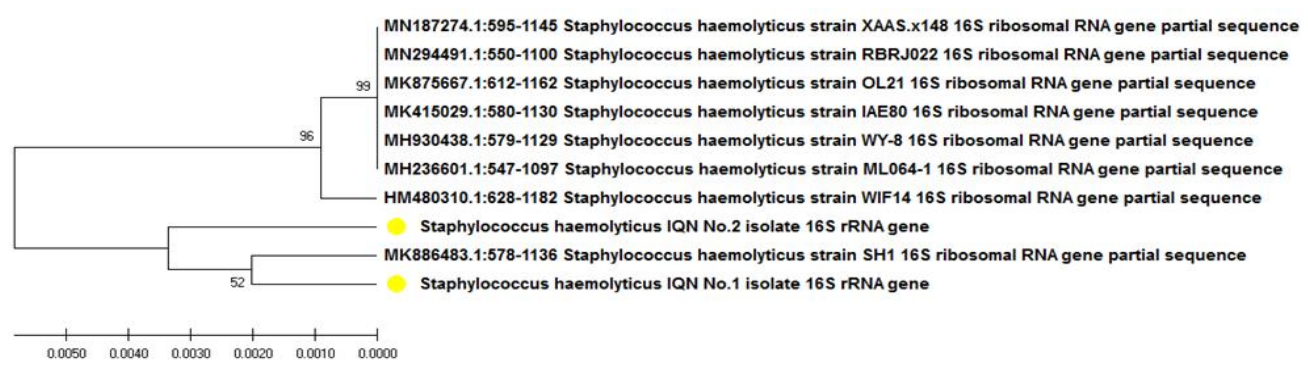

Fig. 2. Phylogenetic analysis of $16 \mathrm{~S}$ rRNA gene partial sequence in local S. haemolyticus MW485614 and MW485615 [IQN. No.1 and IQN. No.2] isolates at total genetic changes (0.005-0.001\%). 
The gel electrophoresis for PCR products of icaA, blaz, mecA, and SodA genes of S. haemolyticus was recorded in 30 (75\%), 23(\%57.5), 32(80\%), and $24(60 \%)$ at 583, 564, 426, $262 \mathrm{bp}$, respectively as represented in Fig 3. The sequence alignment analysis of the icaA gene in local isolates (MW940832 and MW940833) revealed that were 5 substitutions in their linear sequenced DNA, the identities for this isolate were $99 \%$. The phylogenetic analysis showed that two local S. haemolyticus isolates that showed a close genetic relationship with NCBIBLAST S. aureus intercellular adhesion locus at total genetic changes (0.04-0.01\%) as shown in Fig 4. This result agrees with the results of Barros et al. [24] and with the study of Panda and Singh [25] that identified icaA operon in S. haemolyticus that isolated from ocular infections and showed a role this operon in the formation of biofilms in S. haemolyticus isolates.

The sequence alignment analysis of the blaz gene in the local isolate (MW940836) revealed that were 10 nucleotide substitutions in its linear sequenced DNA, while in the local isolate (MW940837) showed 9 substitutions, the identities for this isolate was 98\%. The phylogenetic analysis based on blaz gene partial sequence in local S. haemolyticus isolates revealed that showed a close genetic relationship with NCBI-BLAST S. aureus strain A7 at total genetic changes (0.04-0.01\%) as shown in Fig 5. The results were consistent with Olsen et al. [26] who have confirmed that all penicillin resistance strains were carried the blaZ gene and showed a similar organization of blaR 1 and blaZ. The sequence alignment analysis of the mecA gene in local isolate (MW940834) was shown only 4 substitutions in its linear sequenced DNA, while in local isolate (MW940835) was included 3 substitutions in its linear sequenced DNA, the identities for this isolate was $99 \%$.

The phylogenetic analysis based on mecA gene partial sequence in local S. haemolyticus isolates were showed a close genetic relationship with NCBI-BLAST S. haemolyticus at total genetic changes (1.5-0.5\%) as shown in Fig 6. The current result was consistent with Hussain et al. [27] study who showed that $83.3 \%$ of S. haemolyticus were positive for the mecA gene, whereas inconsistent with the study of $\mathrm{Xu}$ et al. [28] that proved only $22 \%$ of S. haemolyticus isolates were carriage this gene. The sequence alignment analysis of the SodA gene in the local isolate (MW940838) was shown only 2 substitutions in its linear sequenced DNA, while in another isolate (MW940839) was contained 3 substitutions in its linear sequenced DNA, the identities for this isolate was 99\%. The phylogenetic analysis based on SodA gene partial sequence in local S. haemolyticus isolates were showed a close genetic relationship with NCBIBLAST S. haemolyticus at total genetic changes (0.04-0.01\%) as showed in Fig 7. The result was consistent with the study of Poyart et al. [6] that showed the sodA gene constitutes a highly discriminative target sequence for differentiating closely related bacterial species. Generally, all phylogenetic analyses that showed in Figs 4 to 7 revealed high bootstrap values of 98-99\%.

\section{Conclusion}

The 16S rRNA gene is very useful to phylogenies reconstruction because of its evolutionary slow rate, the $16 \mathrm{~S}$ rRNA sequence showed slight variation. The presence or absence of virulence genes in the $\mathrm{S}$. haemolyticus genome and the variation of DNA sequencing among the isolates may explain the differences of the clinical manifestations or reflect the disease severity. 


\section{Acknowledgments}

The authors would also like to thank the staff of Bint Al-Huda Hospital for their assistance during the sample collection. The study was not financially supported.

Conflict of interests: The authors declared that no conflict of interests among them.
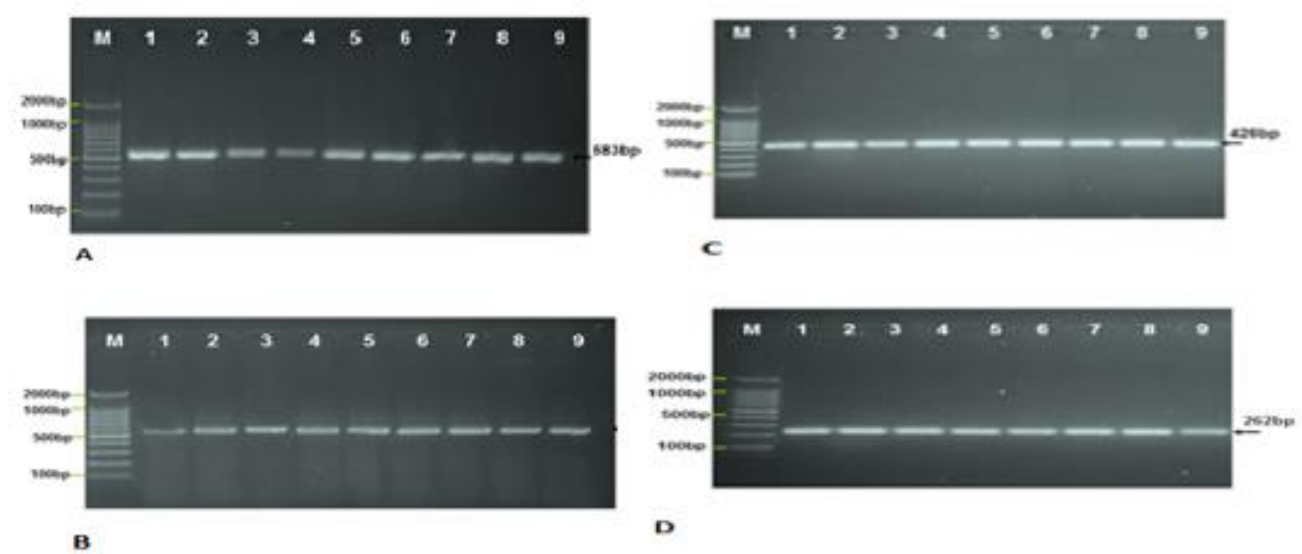

Fig. 3. The PCR product analysis of S. haemolyticus genes. Where Marker ladder [2000-100bp], lanes [1-9] were positive of: [A] icaA gene at 583bp.[B]: blaz gene at 564bp. [C]: mecA gene at $426 \mathrm{bp}$.[D]: sodA gene at $262 \mathrm{bp}$.

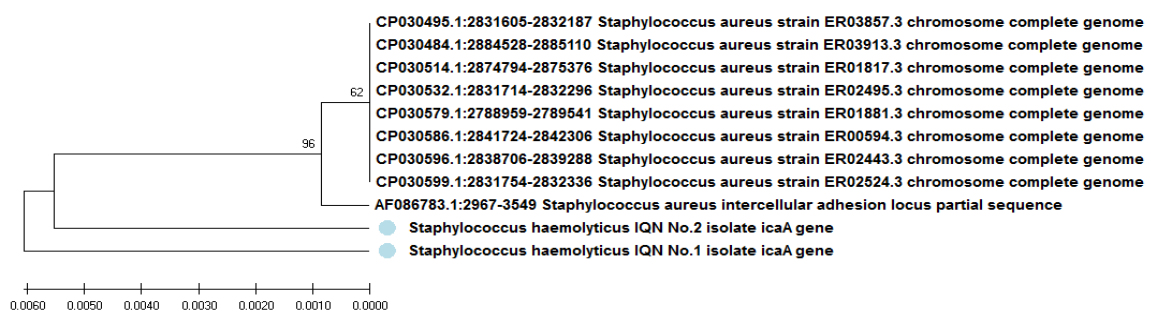

Fig. 4. Phylogenetic tree analysis of icaA gene partial sequence in local S. haemolyticus MW940832 and MW940833(IQN No.1-No.2 ) isolates at total genetic changes (0.04-0.01\%).

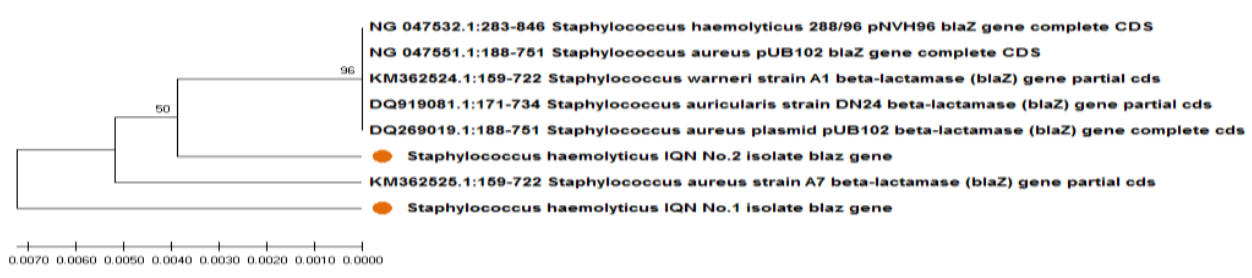

Fig. 5. Phylogenetic analysis of blaz gene partial sequence in local S. haemolyticus MW940836 and MW940837 (IQN No.1-No.2 ) isolates at total genetic changes (0.04-0.01\%). 


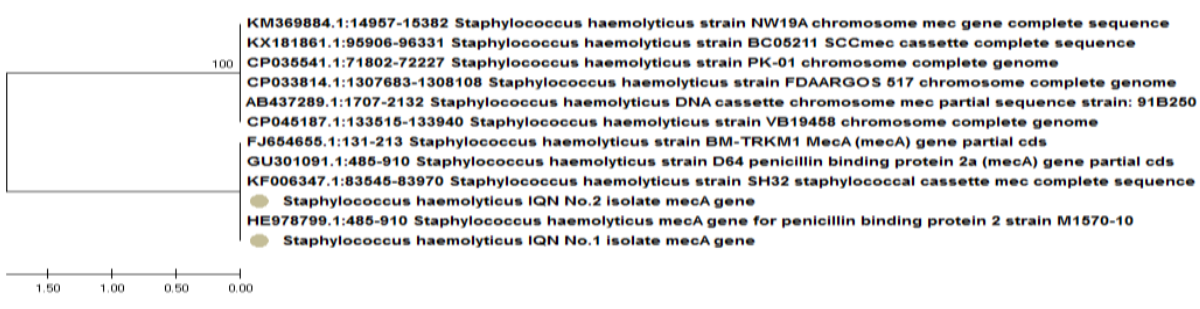

Fig. 6. Phylogenetic analysis of mecA gene partial sequence in local S.haemolyticus MW940834 and MW940835 (IQN No.1-No.2)isolates at total genetic changes (1.5-0.5\%).

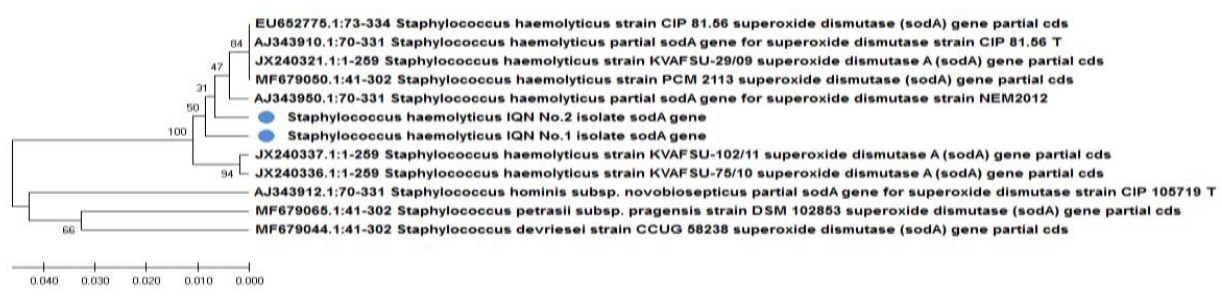

Fig. 7. Phylogenetic analysis of sodA gene partial sequence in local S. haemolyticus MW940838 and MW940839 (IQN No.1-No.2) isolates at total genetic changes (0.04-0.01\%).

\section{References}

[1] Mulu W, Yimer M, Zeneb Y, Abera B. Common causes of vaginal infections and antibiotic susceptibility of aerobic bacterial isolates in women of reproductive age attending at Felegehiwot referral Hospital, Ethiopia: a cross-sectional study. BMC Women's Health .2015; 15 [42]: 1-9.

[2] Sánchez A, Rivera A, Castillo F, Ortiz S. Cervical erosion as result of infectious vaginitis. European Journal of Experimental Biology. 2012; 2[5]:1659-1663.

[3] Sherrard J. Evaluation of the BD MAXTM Vaginal Panel for the detection of vaginal infections in a sexual health service in the UK. Int J STD \& AIDS. 2019; 30[4]:411-4.

[4] Baptista P V, Eleutério J. Diagnosis of vaginitis: time to improve and move on. Jornal Brasileiro de Doenças Sexualmente Transmissíveis. 2020; 32. e203214: 1-3.

[5] Takeuchi F, Watanabe S, Baba T, Yuzawa H, ItoT, MorimotoY, Kuroda M, Cui L, Takahashi M, Ankai A, Baba S, Fukui S, Lee J C, Hiramatsu H. Whole-Genome Sequencing of Staphylococcus haemolyticus Uncovers the Extreme Plasticity of Its Genome and the Evolution of Human-Colonizing Staphylococcal Species. Journal of Bacteiology. 2005; 187[21]: 7292-7308.

[6] Poyart C, Quesne G, Boumaila C, Trieu-Cuot P. Rapid and accurate species-level identification of coagulase-negative staphylococci by using the sodA gene as a target. Journal of clinical microbiology. 2001; 39:4296-4301.

[7] Falcone M, Giannella M, Raponi G, Mancini C, Venditti M. Teicoplanin use and emergence of Staphylococcus haemolyticus: is there a link. Clinical Microbiology and Infectious Diseases. 2006; 12:9697.

[8] Al Laham NH, Rohde G, Sander A, Fischer M, Hussain C, Heilmann D, Mack R, Proctor G, Peters K, Becker C, von E. Augmented expression of polysaccharide intercellular adhesin in a defined Staphylococcus epidermidis mutant with the small-colony-variant phenotype. J. Bacteriol. 2007; 189:4494-4501.

[9] Fredheim E, Aarag G, Klingenberg C, Rohde H, Frankenberger S, Gaustad P, Flægstad T, Sollid J E. Biofilm Formation by Staphylococcus haemolyticus. JOURNAL OF CLINICAL MICROBIOLOGY. 2009; 47[4]: 1172-1180. 
[10] Bouchami O, Achour W, Mekni MA, Rolo J, Ben H A. Antibiotic resistance and molecular characterization of clinical isolates of methicillin-resistant coagulase-negative staphylococci isolated from bacteremic patients in oncohematology. Folia Microbiol. [Praha] .2011; 56. 122-130

[11] Patel JB. 16S rRNA gene sequencing for bacterial pathogen identification in the clinical laboratory. Mol. Diagn. 2001; 6:313-321.

[12] Clsi. Performance Standards for Antimicrobial Susceptibility Testing. 2010. Twentieth Informational Supplement. Clinical and Laboratory Standards Institute, Wayne.

[13] Sambrook J, Green M R. Molecular Cloning: A laboratory manual. Cold Spring Harbor, NY: Cold Spring Harbor Laboratory press. 2012; 1-34.

[14] Goldenberg R, Thompson C. The infectious origins of stillbirth. Am J Obstet Gynecol. 2003; 189[3]: 861-873.

[15] Ohadian S M, Reza M P, Aminharati F. Biofilm formation and antimicrobial resistance in methicillinresistant Staphylococcus aureus isolated from burn patients, Iran. The Journal of Infection in Developing Countries.2014; 8[12]:1511-7.

[16] Guta C D. Microbiological study of antepartum and postpartum vaginal flora. Clinical and laboratory research and therapeutical particularities. 2013. Doctoral thesis, University of Medicine \&Pharmacy of Cralova, Faculty of Medicine.

[17] Koeijers J, Verbon A, Kessels A, Bartelds A, Donkers G, Nys S, Stobberingh E. Urinary tract infection in male general practice patients: uropathogens and antibiotic susceptibility. Urology. 2010; 76: 336-340.

[18] Cerca N, Martins S, Cerca F, Jefferson KK, Pier GB, Oliveira R, Azeredo J. Comparative assessment of antibiotic susceptibility of coagulase-negative staphylococci in biofilm versus planktonic culture as assessed by bacterial enumeration or rapid XTT colorimetry. J Antimicrob Chemother. 2005; 56 [2]: 331 336.

[19] Namvar AE, Asghari B, Ezzatifar F, Azizi G, Lari AR Detection of the intercellular adhesion gene cluster [Ica] in clinical Staphylococcus aureus isolates. GMS Hyg Infect Control. 2013; 8[1]: Doc03.

[20] Ash C, Farrow J A, Dorsch M, Stackebrandt E, Collins MD. Comparative analysis of Bacillus anthracis, Bacillus cereus, and related species based on reverse transcriptase sequencing of $16 \mathrm{~S}$ rRNA. Int. J. Syst. Bacteriol. 1991; 41: 343-346.

[21] Trebesius K, Harmsen D, Rakin A, Schmelz J, Heesemann J. Development of rRNA-targeted PCR and in situ hybridization with fluorescently labelled oligonucleotides for detection of Yersinia species. J. Clin. Microbiol. 1998; 36: 2557-2564.

[22] Janda JM, Abbott SL. 16S rRNA gene sequencing for bacterial identification in the diagnostic laboratory: pluses, perils, and pitfalls. Journal of Clinical Microbiology. 2007; 45:27614.

[23] Ghebremedhin B, Layer F, Ko“nig W, Ko“nig B. Genetic Classification and Distinguishing of Staphylococcus Species Based on Different Partial Gaps, 16S rRNA, hsp60, rpoB, sodA, and tuf Gene Sequences. Journal of clinical microbiology. 2008; 46[3]: 1019-1025.

[24] Barros EM, Lemos M, Souto-Padrón T, Giambiagi-deMarval M. Phenotypic and genotypic characterization of biofilm formation in Staphylococcus haemolyticus. Curr. Microbiol. 2015; 70: 829834.

[25] Panda S, Singh DV. Biofilm Formation by ica-Negative Ocular Isolates of Staphylococcus haemolyticus. Frontiers in Microbiology. 2018; 9[2687]: 1-9.

[26] Olsen JE, Christensen H, Aarestruo F M. Diversity, and evolution of blaZ from Staphylococcus aureus and coagulase-negative staphylococci. Journal of Antimicrobial Chemotherapy. 2006; 57:450-460. 
[27] Hussain Z, Stoakes L, Massey V, DiagreD, Fitzgerald V, El Sayed S. Correlation of oxacillin MIC with mecA gene carriage in coagulase-negative staphylococci. Journal of Clinical Microbiology. 2000; 38[2]:752-4.

[28] Xu Z, Shah HN, Misra R, Chen J, Zhang W, Liu Y, Cutler R, Mkrtchyan H V. The prevalence, antibiotic resistance and mecA characterization of coagulase-negative staphylococci recovered from nonhealthcare settings in London, UK. Antimicrobial Resistance and Infection Control. 2018; 7[73]: 1-10. 